\title{
Relações e substâncias: apontamentos sobre corporalidade e \\ concepção Mbya-Guarani
}
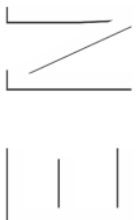

\section{Luna Mendes ${ }^{1}$}

Universidade Federal do Rio de Janeiro

Resumo: Realizo uma revisão bibliográfica relativa a aspectos relacionados à corporalidade feminina entre os Mbya-Guarani, atento para a menstruação e para as relações sociocosmológicas que podem ser ativadas em períodos de vulnerabilidade. Dedico uma atenção maior aos processos de concepção e criação de crianças por entender tratar-se de um tema que dá visibilidade a uma série de valorações relativas a gênero entre os Mbya e também ao modo como substâncias são necessariamente relacionais.

Palavras-chave: gênero; Mbya-Guarani; corporalidade; substâncias.

${ }^{1}$ Doutoranda no Programa de Pós-Graduação em Antropologia Social/ Museu Nacional/UFRJ. Mestre em Antropologia pela Universidade Federal Fluminense, graduada em Jornalismo pela Universidade Federal do Rio Grande do Sul e graduação em andamento em Ciências Sociais pela Universidade Federal do Rio de Janeiro. 


\title{
Relations and substances: notes on Mbya-Guarani corporality and conception
}

\begin{abstract}
This paper is a bibliographic review on aspects related to female corporality among the Mbya-Guarani, attentive to menstruation and the sociocosmological relationships that can be activated in periods of vulnerability. I dedicate more attention to the processes of conception and creation of children because this is a theme that gives visibility to a series of valuations related to gender among the Mbya and also to how substances are necessarily relational.
\end{abstract}

Keywords: gender; Mbya-Guarani; corporality; substances.

\section{Relaciones y sustancias: apuntes sobre corporalidad y concepción Mbya-Guaraní}

Resumen: Realizo una revisión bibliográfica sobre aspectos relacionados con la corporalidad femenina entre los Mbya-Guaraní, atento para la menstruación y las relaciones sociocosmológicas que pueden activarse en períodos de vulnerabilidad. Dedico más atención a los procesos de concepción y creación de niños porque este es un tema que da visibilidad a una serie de valoraciones relacionadas a género entre los Mbya y también a cómo las sustancias son necesariamente relacionales.

Palabras clave: género; Mbya-Guarani; corporalidad; sustancias. 
$\mathrm{N}$ este artigo realizo uma revisão bibliográfica parcial sobre a corporalidade Mbya-Guarani enfatizando aspectos que ajudem a pensar e entender o modo como gênero aparece e é ativado nas relações. As formulações indígenas sobre corpo e pessoa constituem um potente caminho para dar visibilidade às relações de gênero ao informar sobre aspectos das relações sociais ameríndias a partir das diferenças nos modos como domínios da vida social envolvem homens e mulheres, nas agências em torno das práticas cotidianas. Procurei perceber nessa revisão o modo como as substâncias aparecem nas descrições etnográficas, a produção do corpo envolve uma série de práticas que atravessam diferentes domínios da vida cotidiana e que remetem à constante instabilidade dos corpos; consiste em uma manutenção de distâncias e proximidades fundamentais entre seres, e passa por vinculações de gênero. Em síntese, procuro agregar aqui descrições que apontam para como falar em substâncias implica falar em relações.

Realizar uma revisão bibliográfica deste povo, sobre o qual páginas e páginas já foram escritas, é tarefa difícil, qualquer critério adotado para uma revisão deixa de lado muitas etnografias e questões importantes. Para tanto, optei por três recortes principais: trabalhos que tratam da temática corpo e pessoa e que apresentam questões relativas a gênero ou a aspectos do cotidiano; trabalhos formulados a partir de interlocuções com mulheres mbya; e materiais que procuram inserir a descrição etnográfica dos Guarani em um debate mais amplo no campo da etnologia indígena sul-americana (VIVEIROS DE CASTRO, 1996; LIMA, 1996). Assim, as etnografias de Suzana de Jesus (2015), Maria Paula Prates (2013) e Flavia Mello (2006) entraram neste corpus porque além de passar pelos temas de corpo e pessoa, o fazem a partir de um recorte de gênero. Os trabalhos de Elizabeth Pissolato (2007), Valéria Assis (2006) e Martin Tempass (2005) porque trazem questões relativas às produções cotidianas mbya. Compõem ainda essa revisão uma série de outras etnografias que auxiliaram a elucidar determinados pontos: Benites (2018), Lewkowicz (2016), Mendes (2016), Affonso (2014), Pierri (2013), Heurich (2011), Ciccarone (2001).

\section{Breve aporte sobre noções de corpo e pessoa mbya-guarani}

Para entender a constituição da pessoa mbya é necessário olhar para a imbricação entre corpo e pessoa. No sentido de que ser uma pessoa passa pela produção de um corpo específico para tal, processo que está vinculado às relações mantidas, eclipsadas, estimuladas e evitadas por cada um. Valéria Assis (2006) relata um episódio que exemplifica bem essa complexidade: um homem mbya, por ter o sangue misturado (filho de indígena e não indígena), vivia cercado de incertezas acerca das possibilidades de ser aceito na morada dos deuses, mesmo adotando medidas para viver de acordo com um teko porã ${ }^{2}$. A dimensão afetiva e espiritual passa por uma produção corpórea necessária para ser de fato um mbya, parte do que envolve ser mbya é ter corpos distintos daqueles dos demais grupos. Os pro-

\footnotetext{
2 Pierri (2013: 159) ressalta que em determinados casos porã pode ser traduzido por uma noção aproximada de imperecível, qualidade associada aos elementos que existiriam no mundo divino. Porã costuma ser traduzido por belo, bom, bonito. O teko porã opõe-se ao teko axy, o primeiro emula o modo de vida das divindades, o segundo remete ao polo da humanidade (PIERRI, 2013).
} 
cessos de produção de corpo e pessoa remetem, principalmente, aos agenciamentos dificultados ou facilitados pelas relações entre seres, através de um cuidado entre quais vínculos serão estimulados ou eclipsados através dos usos de substâncias, objetos, alimentos, etc. Cabe destacar aqui a centralidade da noção de nhe'e 3 (alma-palavra) para pensar esse tema, de acordo com Suzana de Jesus: "corpos guarani são assim constituídos por substâncias (seja sangue, leite ou comida) e palavras" (Jesus, 2015:128). Alguns autores (MELLO, 2006; PISSOLATO, 2007; HEURICH, 2011) apontam para a impossibilidade de compreensão da nhe'e sem pensar o corpo.

\begin{abstract}
Entre os Mbya, tete é usado para se referir às partes físicas visíveis de um corpo, dos pés à cabeça, mas também para partes internas como o sangue. É a palavra usada também para designar "uma pessoa": peteĩ tete. A alma-divina (ñe’e) também é uma pessoa, mas distinta de tete: a forma com que os Mbya se referiam a ñe'e indicava que tratavam de outra pessoa: era como se estivessem falando de Pedro ou Paulo, de outro alguém: os desejos de ñe'e, os cuidados com ñe'e e as ações que se devem evitar - e realizar - para que ñe'e não se afaste de tete. (HEURICH, 2011: 48)
\end{abstract}

Acerca desse tema cabe realizar uma aproximação com o trabalho de Viveiros de Castro, para quem o corpo não deve ser lido apenas a partir de diferenças fisiológicas, mas como "um conjunto de maneiras ou modos de ser que constituem um habitus" (VIVEIROS DE CASTRO, 2011: 380). Ou seja, depende mais das relações e práticas em que se está engajado do que de características substanciais. Para os Mbya, a nhe'e é incorporada e impõe sua perspectiva, no entanto o corpo precisa continuar a ser estabilizado via fabricação porque segue sendo alvo de disputas de perspectivas que podem ser incorporadas ao longo da vida e com isso implicar mudanças até o limite das transformações.

Nesses processos, as relações ganham centralidade. Manter ou não relações com pessoas e seres também tem a ver com alimentação, uso de objetos, emoções; no modo como se ativam ou eclipsam relações. Nesse sentido, a produção corporal não remeteria a uma domesticação do corpo pela cultura, o corpo é a expressão do sujeito, é aquilo que se mostra aos outros. E é por aquilo que se mostra aos outros em períodos de vulnerabilidade que a incorporação de outras perspectivas seria facilitada o que, portanto, aumenta a suscetibilidade à transformação corporal. Assim, o corpo figura como local de disputa de perspectivas: a porção espiritual divina, nhe'e; a sombra, alma telúrica, angue; os estados afetivos que favorecem a incorporação de determinados ja (donos); os estados corporais alcançados através dos alimentos que vão deixar um corpo quente, frio ou brando; etc. É preciso ressaltar que os diversos componentes da pessoa mbya implicam dimensões verticais e horizontais nessa fabricação, Hélène Clastres apontou para essa ambivalência dos habitantes da terra: "dotados de uma alma-palavra, ligada ao esqueleto, também possuem uma 'alma' ou 'natureza' animal, vinculada ao sangue e à carne: teko achy kue é o produto da existência má, aquilo pelo que participam da animalidade" (CLASTRES, 1978: 94). É importante ressaltar que essas dimensões não constituem categorias taxônomicas fixas, mas se atualizam nas relações que são estabelecidas com os diferentes seres que povoam o cosmo.

Mendes (2016) percebe a pessoa guarani como dividual, cuja produção se dá por contraste com outras categorias de seres. $\mathrm{O}$ autor define linhas que conectam os Guarani a categorias de seres; o deslocamento em direção a cada um desses polos ativa ou eclipsa determinados aspectos da pessoa mbya. Comer carne crua,

3 A pessoa mbya seria formada, no mínimo, por uma parte divina nhe'e - um conceito central na etnografia guarani que costuma ser traduzido como 'alma-palavra' - que é enviada pelos deuses e está vinculada ao que a pessoa é, seu nome, as palavras que profere; e uma parte telúrica angue traduzida como sombra e vinculada aos demais seres que habitam o mundo mbya. 
por exemplo, aguça o aspecto animal; carne cozida, o humano. O que a pessoa mbya é dependeria das relações que são estabelecidas e também das relações que são eclipsadas, mas que permanecem nesse "feixe de afecções"; enquanto possibilidades de ativação, no sentido de que remetem a perspectivas passíveis de incorporação.

Assim, quando se trata de corpo e pessoa, a instabilidade é constituinte dos diferentes modos de ser e estar no mundo, no sentido de que tanto corpo como humanidade são uma perspectiva (definidos por relações). O que conta como corpo para os ameríndios não envolveria somente um corpo "natureza", fisiológico e substancialista; mas algo mais próximo de um corpo que figura como centro de uma série de relações possíveis; esse corpo produzido por afecções (VIVEIROS DE CASTRO, 2011).

\section{Sangue e substâncias}

Para os Mbya a diferença nas relações reside principalmente nos corpos, seus corpos não são os mesmos dos outros seres, suas substâncias diferem. Nesta direção, um tópico recorrente nas etnografias guarani é o risco da mistura de sangue através de relações sexuais (PIERRI, 2013; PRATES, 2013; ASSIS, 2006; TEMPASS, 2005). Diz-se dos jurua (não-indígenas) que por terem o sangue diferente podem tornar doente o guarani, porque o sangue mbya é mais fino e mais fraco que o dos jurua: "nossos corpos, nossos fluidos não são os mesmos ou, no mínimo, não com a mesma potência" (PRATES, 2013: 31). Como vimos, filhos de casamentos interétnicos não teriam corpos estritamente mbya e correriam o risco de não serem aceitos na morada dos deuses mesmo seguindo uma vida inteira de cuidados e rituais (ASSIS, 2006). Cabe ressaltar que o sangue não é entendido aqui em seu aspecto estritamente biológico, mas envolve dimensões afetivas, mentais e espirituais. A administração dos fluxos de sangue não se restringe ao âmbito corporal, mas reverbera na saúde, no teko porã, nas comunicações com os deuses, nas relações. Misturar o sangue provoca desequilíbrios: "o sangue juruá entra por via genital e ao circular pelo corpo mbya enfraquece até mesmo o pensamento do guarani" (PRATES, 2013:31). Nesse ponto, as mulheres por sangrarem com mais frequência seriam menos expostas aos riscos de contaminação, pois junto com a menstruação sai o sangue que provoca desequilibrio; para atenuar os mesmos riscos os homens precisariam passar por intervenções, é preciso: "se arranhar fortemente com galhos de árvores nas pernas e braços a fim de fazer seu corpo sangrar e assim cessar a contaminação" (PRATES, 2013: 31).

O compartilhamento de substâncias transforma marido e mulher em parentes de sangue (yguyretarã), a troca de constantes fluidos corporais (apyndjy) além da comensalidade é capaz de ativar o parentesco (MELLO, 2006). Ainda sobre sexo: "o ato sexual em si é visto como uma 'mistura de sangue', e por isso os mais velhos dizem que dormir com brancos leva à morte, porque o sangue se mistura também no corpo daqueles que o fazem" (PIERRI, 2013: 177). Prates (2013) observa as mesmas elaborações referentes ao sangue com relação ao leite materno. Naturezas diferentes envolvem corpos e substâncias específicas que produzem efeitos nos corpos com os quais entram em contato, seja através da relação sexual, da amamentação ou outros compartilhamentos. Por esse motivo bebês mbya são diferentes de bebês jurua, não possuem os mesmos corpos, não podem ser submetidos às mesmas substâncias. Sobre uma família mbya cujo bebê após o parto precisou ficar internado em um hospital, Ferreira descreve: "A famí- 
lia indígena ficou assustada diante da possibilidade do neném estar sendo alimentado com leite de mulher branca, porque isso lhe causaria outras doenças futuramente" (FERREIRA, 2013: 1156).

O sangue aproxima-se dos elementos associados aos aspectos telúricos da existência, e pode ser associado ao tupichua ("princípio vital da carne crua", Clastres, 1978:96): "Proveniente da carne crua, mas também do sangue, de uma forma geral, tupichua pode aproximar-se da pessoa e transforma-la em jaguar: o caçador mesquinho e solitário, comendo sozinho na floresta, atrai inevitavelmente tupichua" (HEURICH, 2011:113). Da mesma forma a mulher menstruada precisa evitar rios e matas porque seu corpo nessa condição atrai seres que devem ser evitados. O tupichua teria se originado da desavença mítica com os jaguares, portanto tudo que não é guarani não corre o risco de ter tupichua (carnes compradas em mercado, animais domésticos) (TEMPASS, 2005).

Prates (2013) relaciona o tupichua com os ja (donos), como uma ação decorrente da mediação que os ja fazem entre relações humanas e não humanas: "o tapichua enquanto princípio vital é a ação decorrente dessa troca, uma vez que ao alocar-se na carne e no sangue da pessoa tende a enfraquecer sua ñe'e e, por consequência, desestabilizar e viabilizar o -jepota" (PRATES, 2013: 211). Sentimentos como a raiva e o ciúme provocam o nhemboaxy - sentir pena de si mesmo, ser digno de pena (PRATES, 2013), enfraquecem o pensamento, e consequentemente o corpo, tornando a pessoa vulnerável a transformações corporais. Conforme Benites: "os cuidados com o corpo feminino são muito importantes para a construção do ser mulher guarani e evitar o estado de poxy, de vulnerabilidade, dos efeitos do sangue, tuguy" (BENITES, 2018: 11). Esses estados propiciam o risco de incorporar o tupichua e outros ja que circulam no corpo enquanto substâncias competindo por uma apropriação da perspectiva de nhe'e (PRATES, 2013) e incitando desejos específicos que se aproximam dos aspectos atribuídos à antissocialidade mbya (comer carne crua, andar sozinho e à noite). Essas substâncias transformam e enfraquecem o sangue mbya em um processo similar ao que torna perigoso o contato com o sangue dos brancos, porém mais intenso. Quando os donos das emoções se apoderam do corpo humano, a agência da pessoa torna-se limitada e são necessárias sessões de cura xamânica para que volte a si (PRADELLA, 2009).

Os riscos de transformações e as relações das mulheres com a terra e o sangue são demarcadoras do seu lugar nas comunicações e agenciamentos sociocosmológicos mbya. Pierri (2013) aponta para uma associação entre solo e substâncias poluidoras. O sangue aciona comunicações com a porção telúrica do mundo mbya, motivo pelo qual durante a menarca um dos procedimentos envolve colocar as meninas em uma cama alta (chamada nimbé). Porém, ao mesmo tempo em que se vincula aos riscos da existência no mundo perecível, a terra é condição fundamental para a manutenção de um mbyá rekó (jeito guarani). Conforme Ciccarone (2001), o ciclo de existência terrena conecta-se com os cultivares, a agricultura e a alimentação: o ato inaugural de um tekoa envolve plantar as sementes na terra da nova morada. Ao descrever o conceito de 'corpo-território', Benites (2018) associa território ao tekó (modo de ser): "Teko significa 'modo de ser'. Tekoha é onde se constrói esse modo de ser, cada corpo é um território. Por isso, para nós existem vários teko" (BENITES, 2018: 70). A autora destaca que são os cuidados específicos com o corpo feminino que ajudam a entender o modo como diferentes teko coexistem no mundo: 
as mulheres sempre existiram na terra para habitar a terra, por isso, onde os corpos das mulheres estão enfraquecidos, as terras também estão doentes, ficam mais poxy (revoltado). (BENITES, 2018: 83)

Benites (2018) conecta a emocionante história de Nhandesy4 com o modo de vida das mulheres guarani, para a autora, assim como as mulheres, Nhandesy é da terra: "O corpo de Nhandesy é concreto, é chão onde se pisa. O que dá a vida, dá alimentos é o corpo da Nhandesy" (BENITES, 2018: 90).

\section{A menstruação das mulheres e os cuidados com as relações sociocosmológicas}

O sangue também aparece em alguns processos centrais na produção da corporalidade feminina mbya, destaco aqui tanto a primeira menstruação e os cuidados necessários durante esse período quanto os ciclos menstruais de maneira geral como momentos de cuidados.

Na produção da corporalidade feminina mbya, a menstruação aparece como sendo a grande demarcadora das fases da vida de uma mulher, a partir da menarca - iẽngue -, a menina passa a ser reconhecida como kunhã ta $\tilde{\imath}$ (Jesus, 2015: 200) 5. Conforme Ciccarone (2001: 62), nos dias da primeira menstruação, as meninas precisariam permanecer com a cabeça coberta por um pano, ficando reclusas em casa. De acordo com Jesus (2015), a primeira menstruação demarca uma nova posição social: as meninas têm o cabelo cortado pela mãe ou avó e passam por uma alimentação mais restrita que visa produzir tanto o corpo feminino, quanto o das crianças que a mulher possa vir a criar.

A iẽngue é um período de resguardo que envolve uma dieta alimentar mais rigorosa: "O sangue a deixa exposta, sensível e vulnerável, podendo atrair olhares de diferentes seres, por isso é bom não sair de casa, pelo menos enquanto o sangramento perdurar” (Jesus, 2015: 125). A relação entre o sangue e a visibilidade que ele suscita para outros seres aparece também em Mello (2006) que descreve a importância de meninas menstruadas não fixarem o olhar sobre plantas, animais e até mesmo pessoas. Ver implica também ser vista, ser vista como congênere e ver outros seres como tal pode ser o suficiente para dar início ao processo de transformação chamado jepota.

A bibliografia sobre outros povos indígenas também auxilia a pensar esse fenômeno. Conforme Belaunde, o cheiro do sangue torna a pessoa visível aos seres que normalmente não a vêem, sendo tanto um operador de visibilidade quanto de sedução: "El olor de la sangre tiene un efecto perspectivístico, efectúa un cambio de cuerpo y abre las cortinas de la visibilidad entre diferentes perspectivas" (Belaunde, 2008: 54). McCallum (2001) observa que o sangue menstrual, assim como outras substâncias corpóreas, conecta humanos e espíritos porque quebra a separação entre domínios. Seu cheiro conecta e torna visível o que normalmente é invisível.

A força do sangue e as potências que ele é capaz de acionar tornam a mulher menstruada um canal de comunicação que se estende para seus parentes; o útero

\footnotetext{
4 Para narrativa completa de Nhandesy ver Benites (2018).

5 Prates (2013) registra a menarca como estar nimbé que segundo a autora seria uma referência à cama alta onde ficam as meninas recém menstruadas, mas também seria usado para dizer que uma menina "virou mocinha", a autora também registra o uso de iengué como "menina que já menstruou". Já Ciccarone (2001) refere-se ao período da primeira menstruação como ogwapy .
} 
(memby ryru ${ }^{6}$ é tido como o principal canal responsável por esse transformacionismo potencial (Mello, 2006). É preciso atentar para a instabilidade corporal acionada pelo sangue exposto, nesses períodos a mulher não deve "preparar a comida, andar sozinha no mato, lavar-se com água corrente [...]. O sangue é um atrativo para os animais. Deve-se ao máximo camuflar seu cheiro, dormindo longe da terra, evitando o contato com a água" (Prates, 2013: 193). Os perigos das aproximações com o solo (Ciccarone, 2001; Pierri, 2013) são evocados enquanto índices dos riscos de tornar-se visível para os outros seres, indicando a relação já vista entre sangue e o lado telúrico da pessoa que precisaria ser escamoteado. Não seguir as prescrições que controlam a potência do sangue envolve o risco de passar a comer e a ter relações com outros seres, fazer parentesco com outros que não humanos e com isso transformar-se (jepota).

É importante salientar novamente que a vulnerabilidade ativada pelo sangue não envolve apenas um corpo enquanto substância, pois as transformações capazes de atingir o corpo não podem ser dissociadas de seus efeitos mentais e espirituais. Benites (2018) destaca a importância dos cuidados com os pensamentos como parte importante da corporalidade feminina, pois segundo a autora é na akã (cabeça/pensamentos) que as mulheres mais são atingidas pelos efeitos do sangue. Assim, corpo, mente e alma estão em uma relação de afetação mútua:

\begin{abstract}
A mulher quando em seu ciclo menstrual é mais vulnerável ao ataque dos ja por seus "pensamentos". Esses estados afetivos possuem ja, que extrínsecos ao corpo da mulher lhe atingem em doses cumulativas. É de suma importância proteger os sentidos, sobretudo a audição e a visão, por isso o cabelo deve ser cortado (na menarca) e a cabeça coberta quando se está menstruada: é na cabeça que mora o perigo de se fazer atacar pelos ja das emoções. (PRATES, 2013: 195)
\end{abstract}

A menstruação feminina também é nominada como Jaxy py - estar com Lua, ou estar casada com Lua (HEURICH, 2011: 31). Entre os Mbya, Jaxy [Lua] é o ser mítico criado por Kuaray [sol] a partir de Nhandesy7. A menstruação feminina teria sido ocasionada por Jaxy. É referência comum nas narrativas ameríndias a relação incestuosa e sem consentimento de Lua com uma parente do sexo feminino que, para o identificar, marca seu rosto com alguma substância, restando a ele subir aos céus enquanto refúgio e lembrança que faz recordar a todos dessa relação - estar com Lua é sinônimo de estar menstruada para diversos povos ameríndios (BELAUNDE, 2008). Outra leitura possível das relações de Lua com o universo feminino é sugerida por Belaunde (2008) que vê nas narrativas míticas uma relação com o parto.

A menstruação se origina em uma relação cruzada, isto é, as mulheres menstruam por causa da agência masculina mítica. Como registra Ana Affonso: "Diz Kerexu que, quando criança, morria de medo de Jaxy, pois lhe diziam, constantemente, que estava chegando a hora em que deveria se casar com um homem muito, muito velho, cujo pênis, de tão grande, a faria sangrar sem parar" (AFFONSO, 2014: 106). Para a autora, essa narrativa possibilita pensar a menstruação não apenas como o anúncio da sexualidade, mas das relações de afinidade. Conforme Mello, Jaxy seria o primeiro marido das mulheres:

Contrariado por ter que partir deste mundo e aqui deixar suas namoradas humanas, Djatchi exige ao irmão e aos outros deuses, seus parentes que chamavam sua presença,

\footnotetext{
${ }^{6}$ São poucas as etnografias que descrevem ou mencionam a noção de útero, Pissolato (2007) registra útero como memby ryru, Mello (2006) traduz útero por memby. Pierri (2013) e Lewkowicz (2016) mencionam memby como fazendo referência ao parto.

7 Em algumas narrativas Jaxy é criado a partir da semente do milho (Assis, 2006); em outras a partir dos ossos de Nhandesy (MELLO, 2006; PRATES, 2013; BENITES, 2018) e em outras ele teria sido criado a partir da folha de Kurupica'y (HEURICH, 2011; PIERRI, 2013). Para narrativa completa de Nhandesy ver Benites (2018).
} 
que em troca de sua partida, todas as mulheres deveriam ser suas esposas, antes de terem seu primeiro marido. Daquele dia até hoje, as mulheres menstruam porque Djatchi "mexe" com as moças quando elas estão se tornando mulher. O sangramento mensal que as mulheres têm é um reflexo, um sinal da ação sobrenatural de Djatchi, o "primeiro marido" das mulheres. Djatchi ire é um dos termos para designar a menstruação. Quando uma mulher queixa-se de dores, fica brava, ou recusa ter relações sexuais, seu marido zomba, rindo e comentando em público que ela está djatchi ire ("na lua”) e que seu primeiro marido voltou para ela. (MELLO, 2006: 171)

As narrativas citadas acima possibilitam perceber a menstruação produzida por Lua como estando relacionada a essa alteridade potencial presente tanto no sangue menstrual quanto na placenta e no sangue do pós-parto. Aspectos relacionados à menstruação são capazes de acionar relações, é através dela que parentescos podem ser feitos ou desfeitos, a decisão sobre a reprodução e sobre com que seres irá se reproduzir cabe às mulheres, tendo assim um lugar importante na manutenção sociocosmológica do mundo mbya.

\section{Os processos de concepção e criação de crianças}

O processo de concepção de crianças situa-se dentre as relações em que a agência feminina ganha centralidade. Suzana de Jesus (2015), tendo realizado seu campo a partir de diálogos principalmente com mulheres, aponta para a agência feminina na produção da pessoa de uma maneira geral, não apenas com relação à gestação. A atenção para a criação das crianças seria eminentemente feminina por ser o corpo das mulheres aquele preparado para tal processo: "a produção feminina de corpos permeia o período considerado como de vida fértil da mulher, enquanto a produção masculina, no contexto da relação de complementaridade, começa na concepção" (Jesus, 2015: 203). A autora opta por separar esses processos para:

Demonstrar o quanto a ideia de fabricação de corpos também foi sendo produzida, ao
longo da história da etnologia, como uma compreensão organizada por meio de cate-
gorias que diziam respeito a uma produção masculina de corpos. Neste sentido, ao se
elencar substâncias corporais envolvidas na fabricação do corpo como sendo sangue e
sêmen, e sendo o sêmen uma substância masculina, a ideia de concepção volta-se ex-
clusivamente à fecundação e direciona-se para os simbolismos envoltos no protago-
nismo masculino. (JESUS, 2015: 203)

Relatos sobre a produção dos corpos femininos para a gravidez aparecem também em Pierre Clastres (1995): entre os Aché, o jaycha bowo seria o procedimento em que com uma pedra "o escarificador corta a pele desde a base dos seios até o sexo, duas vezes de cada lado, em forma de arco [...]. Depois, ele enche o espaço assim determinado de talhos mais curtos, curvos também, que estriam toda a extensão do ventre" (CLASTRES, 1995: 117). Essas escarificações feitas após a menarca preparariam o corpo da menina para a gravidez, além de dar a ele uma forma arredondada, considerada bela para os Aché. No relato do autor essa produção passa pela agência masculina, pois é o padrinho da menina o imbuído de fabricar seu corpo. Entre os Mbya, no entanto, há uma fabricação paralela de gênero: são as mulheres mais velhas que se encarregam de fabricar o corpo das meninas mais novas.

O processo de concepção de crianças entre os Mbya é chamado oñembapyka, expressão que Valéria Assis (2006: 87) traduz por "dá-lhe assento, provê-la de assento". Entende-se que a concepção envolve o envio de nhe'e pelos deuses, cabendo à mãe e ao pai completar o processo: "Conceber para os Mbyá é entendido como a vinda de uma nova alma que se assenta no ventre de uma mulher. A via que traz essa alma do mundo divino para o ventre feminino é o apyka, o banco 
ritual" (ASSIS, 2006: 87). Flávia Mello descreve a gravidez como sendo o momento em que "durante um ato sexual os nhe'erukuery enviam um espírito para morar no memby (útero) daquela mulher" (MELLO, 2006: 144).

Cabe atentar à noção de banco [apyka], já que é através dele que a nhe'e é levada ao útero [memby], onde toma assento; nos rituais o banco é elemento fundamental para viabilizar a comunicação extra-humana. O apyka (Assis, 2006) é um banco de madeira, pequeno e individual que em geral não ultrapassa os vinte centímetros e "é produzido preferencialmente pelos homens, geralmente próximo ao período que antecede aos rituais como o de revelação do nome (kyrĩngue Ñemongarai/ñembo'ery) ou de perfuração do lábio (nombokuavéima, este cada vez mais raro nos teko'a do Rio Grande do Sul)" (ASSIS, 2006: 88). O banco, segundo a autora, é um objeto masculino e tem um uso tanto cotidiano quanto ritual. No primeiro caso ele é denominado guapya $a^{8}$, já "nos momentos rituais, que necessariamente acontecem no interior da opy, o banco é transferido para lá, para que o xamã se sente nele e profira as palavras-cantos rituais. No interior da opy ele é apyka, pois que se torna imbuído de características transcendentais" (ASSIS, 2006: 88). O banco pode ser esculpido segundo moldes zoomórficos: tartaruga, quati, tamanduá, tatu; porém tal molde não é obrigatório para que seja um apyka.

O apyka é entendido como uma via de comunicação com os deuses, pois através dele é possível acessar o mundo divino. Como relata Assis, o apyka seria uma espécie de canoa através da qual pode-se viajar entre mundos: "O acesso permite conversar com as divindades, receber suas palavras, ir ao seu encontro quando na morte e receber almas. O apyka também é mencionado como a via que permite

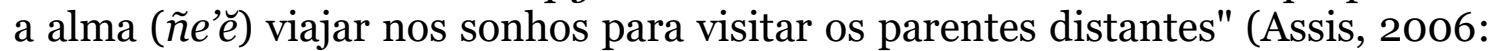
88). No apyka senta-se o xamã que busca a concentração para proferir palavras inspiradas, ele proporciona a postura corporal adequada "para as atividades que requerem reflexão, pensamento e oratória. Segundo Perumi, é preciso estar ereto para que as palavras inspiradas entrem no ser Mbyá através da coronilha (região superior da cabeça)" (ASSIS, 2006: 89).

Entre os Macuna - povo de língua tucano oriental -, o banco também é referido enquanto instrumento que propicia a postura corporal adequada para escutar e pronunciar palavras de oração e conhecimento, como descreve Luisa Belaunde (2008):

El concepto de banco (kumu) tiene múltiples significados. En un sentido material, el banco es el asiento tallado de madera utilizado por los hombres «pensadores» (kumua) para mambear coca y inhalar rapé de tabaco, conversar en las noches en el mambeadero y celebrar rituales de curación. Es tal la asociación entre el conocimiento de un pensador y su banco, que se considera que los bancos de los grandes pensadores representan al cosmos. Su uso está reservado a los hombres pensadores. Las mujeres se sientan en butacas o en el suelo con las piernas cruzadas. (BELAUNDE, 2008: 130-131)

Ainda em Belaunde é possível encontrar referência ao trabalho de Mahecha que também associa o conceito de banco a um sentido corporal: "El banco de una persona es su centro de apoyo interno, en el que se depositan su energía y sus conocimientos, volviéndose parte de su cuerpo" (BELAUNDE, 2008: 132).

Entre os Mbya, a nhe'e está associada aos ossos, assim, sentar-se com a coluna reta é deixar fluir a comunicação com os deuses, "estar no apyka significa estar reproduzindo a mesma posição de Ñanderu" (ASSIS, 2006: 86). O apyka

${ }^{8}$ Guapya pode ser traduzido como lugar onde se senta, a palavra não faz referência direta à diferença entre uso cotidiano e ritual. 
envolve uma afecção corporal que reforça o canal de comunicação humano e extra-humano e está vinculado a uma agência masculina. Benites (2018) destaca o sentar-se como um estado de espírito importante para a corporalidade feminina: "sem estar no estado de guapy - 'sentadas', calmas, tranquilas, em silêncio - facilmente a mulher se descontrola, o 'sangue sobe à cabeça'" (Benites, 2018:10).

As práticas que se sucedem após o 'tomar assento', que envolvem a fabricação do corpo da criança durante a gravidez, implicam tanto a agência masculina quanto a agência feminina através dos alimentos e das relações. Daí em diante uma série de prescrições são evidenciadas de modo a selecionar conjuntos de afecções a serem ou não transferidos ao feto; práticas que abarcam os mais diversos episódios da vida cotidiana: "é comum dizer que é preciso que os pais e mães mantenham o pátio de suas casas limpos durante o período da gestação de um filho. A não observação desse cuidado é o que explica o nascimento de crianças que têm o corpo coberto com muitos pelos" (PIERRI, 2013: 182).

As práticas alimentares centralizam o conjunto de cuidados que pai e mãe devem ter ao longo da gravidez. Nesse período, a mulher é a que mais deve tomar cuidado com aquilo que ingere, uma vez que ela produz o corpo do bebê através daquilo que come, enquanto o homem produziria o corpo do bebê através de sucessivas contribuições de sêmen (MELLO, 2006). O trabalho de Tempass reforça a colocação de que durante a gravidez as principais restrições envolveriam a mãe, seus interlocutores: "negaram firmemente que os homens tenham que manter qualquer controle alimentar durante a gravidez de sua mulher. Todos responderam a minha pergunta dando boas gargalhadas, me informando que os homens não ficam grávidos" (TEMPASS, 2005: 116). A principal restrição para a mulher são os alimentos geminados, pois o contato com esses alimentos poderia provocar o nascimento de gêmeos, algo abominado entre os Mbya: "de uma maneira geral, a gestante deve manter-se afastada de qualquer coisa que se apresente em duplicidade. Pois que as coisas também possuem agência e podem afetar e influenciar na gestação" (ASSIS, 2006: 97). Entende-se que ao nascerem gêmeos, um daqueles inevitavelmente seria desprovido de $n h e ' e$, provocando assim um perigoso desequilíbrio cosmológico9.

Existem pontos de vista distintos com relação à participação das substâncias corpóreas femininas e masculinas ${ }^{10}$ na produção do feto. Para Prates (2013): "É o sêmen do homem que dá forma ao sangue e à carne da criança, enquanto os ossos estariam relacionados com a sua alimentação e conduta" (PRATES, 2013: 234). No entanto, Mello entende que é o sêmen que faz crescer o bebê: "Durante o ato sexual (djapirá) o homem introduz no corpo da mulher tcherendyrai (substância que alimenta o mintãim), o faz crescer, indicando que esta substância age diretamente nos ossos (tchedjopy) do feto" (MELLO, 2006: 156). A ausência de relações sexuais consecutivas condenaria o feto a certa fraqueza, apesar de não interferir em seu desenvolvimento. Após o nascimento sucedem-se diferentes estágios de formação óssea, quando começa a mamar: "o bebê passará a desenvolver o tchekangüe, uma forma distinta de osso, um osso de humano e não mais de espírito como é o tchedjopy, que acompanhará o desenvolvimento e crescimento do corpo" (MELLO, 2006: 156).

O dar assento, oñembapyka, como é nomeada a concepção de crianças, indicaria o estabelecimento de uma instabilidade corporal feminina, posto que tornaria aberta uma via de comunicação extra-humana. À mulher caberia a formação

\footnotetext{
9 De acordo com Assis (2006: 97), "o nascimento de gêmeos significa que uma alma ruim (ñe ĕ vai, ãngue ou mbogua) 'pegou carona'. Ou seja, um dos gêmeos é uma alma mandada pelas divindades, mas a outra não, pois as divindades nunca mandam duas almas de uma vez só".

${ }^{10}$ Há uma relação de quase equivalência entre sêmen e sangue, como apontam Prates (2013) e Pierri (2013).
} 
corporal do bebê através da ingestão de alimentos e dos cuidados com as relações que estabelece, por estar em um estado de vulnerabilidade em que o acesso a outros mundos se torna facilitado. Mello descreve as mulheres grávidas como xamãs em potencial: "por ter, através do feto que carrega, a faculdade de falar em sonhos com Tupãcy, a mãe dos trovões e dos caminhos" (MELLO, 2001: 53). Os cuidados com o feto são referidos na narrativa mítica acerca de Kuaray ${ }^{11}$; é através das comunicações estabelecidas via feto que Nhandecy (mulher e grávida) percorre os caminhos em busca de Nhanderu; por tratar mal o feto - que irritado interrompe a comunicação com a mãe -, Nhandecy escolhe caminhos errados e acaba por se encontrar com as onças e ser devorada por elas. A mulher grávida deve atentar para aspectos de suas relações: "é preciso redobrar os cuidados com os lugares e companhias. A mulher grávida, em especial, deve evitar estar só, principalmente ao realizar incursões na mata" (ASSIS, 2006: 99). As prescrições ressaltam aquilo que é entendido enquanto comportamento social, já que as relações que podem se estabelecer na mata são de outra ordem: a mulher grávida opera enquanto agente de relações extra-humanas, correndo riscos maiores por seu estado corporal. A agência masculina entra como contrapeso a esses riscos: "Estando com a criança em seu ventre, a mulher também está próxima da esfera divina, em uma situação que lhe oferece perigo. O homem tem a função de vigiar o perigo e de ajudá-la a proteger-se dos seres que podem lhe afetar de modo negativo nesta terra" (JESUS, 2015: 128).

Além de uma atenção às relações extra-humanas, cabe principalmente à mulher o cuidado com as relações sexuais com outros homens. Mello aponta para o quão relevante é a conduta dos pais, mas principalmente a da mãe que "durante um nhangarekó (namoro, paquera, envolvimento físico) é determinante na constituição do nhe'e da mintãim (criança) que virá a nascer" (MELLO, 2006: 144). A autora faz uma observação interessante acerca de relações com irmãos do pai; o perigo da relação sexual com outros homens teria a ver com diferentes sêmens produzirem gêmeos, o que não aconteceria caso os homens fossem irmãos, pois teriam o mesmo sêmen:

\begin{abstract}
A noção de equivalência nas essências reprodutoras de dois irmã/os paralelos aparece em várias esferas do pensamento Guarani. Na terminologia, os sobrinhos paralelos são chamados de filhos, o que não acontece com os cruzados (memby kurin para mulheres e radjy e ray kurin para homens, literalmente filhos menores em todos os casos). Em casos concretos de casamentos sororais, por muitas vezes as pessoas me afirmam que os filhos de mesma mãe e pais irmãos são tão irmã/os quanto os filha/os de mesmo pai e mesma mãe. O mesmo não acontece com irmã/os filha/os de pais diferentes, que pertencem à categoria de irmã/os, mas ocupam uma categoria mais distante. Essas nuances entre a proximidade do/as irmã/os do mesmo sibling têm vários graus, o que interfere na consideração sobre o incesto. Os filha/os de mesmo pai e mães diferentes estão um pouco mais distantes, principalmente porque em geral não vivem juntos, não compartilhando o parentesco por consubstancialização. (MELLO, 2006: 146)
\end{abstract}

Prates descreve uma conversa tida com uma mbya que compartilhava o marido com sua irmã: "Enquanto conversávamos sobre as crianças que brincavam ao nosso redor, ela não diferenciou seus filhos dos de Para Kerechu e quando insisti a respeito, por observá-la chamar a todos de che memby/meu filho, ela disse: ‘são vários da barriga de minha irmã, outros da minha”" (PRATES, 2013: 135). Mello observa o vínculo visceral existente entre mãe e bebê: "Quando vou dizer em guarani 'nasceu o filho de fulana', eu digo: 'Djerá ae memby', literalmente, o útero de fulana floresceu, frutificou, germinou" (MELLO, 2006: 155). Segundo Benites (2018: 12): 
memby, falando na língua guarani e traduzindo, é uma coisa que nasce do mesmo corpo e sempre fica ali grudada. As espigas de milho, por exemplo, são awati memby porque surgem do tronco, 'pé' do milho. [...] A estrutura do nosso corpo está ligada diretamente aos nossos filhos(as), mantendo uma relação próxima com eles, a exemplo da árvore e seus galhos, diferentente dos homens que têm formas distintas de nomear, entender e se relacionar com os filhos e as filhas.

O parto é um momento feminino: "o nascimento da criança é um momento vivenciado e gerenciado pelas mulheres. Segundo Maria, a parturiente - principalmente quando são mulheres inexperientes - é assistida por uma ñandecy. Esta é a grande mãe, a figura feminina referencial de uma família extensa ou grupo local" (ASSIS, 2006: 99). Em sua tese Mello (2006: 148) realiza uma detalhada descrição da hora do parto [Oikotama mintãin]:

\begin{abstract}
A parteira põe água para ferver em uma guapepó (panela grande). Depois dá um pouco desta água misturada com cinzas para a mãe beber e a criança nascer mais rápido. Quando o parto é fácil, depois que toma a água, a mãe senta na posição de cócoras, começa a fazer força e logo a criança "vem". Se o parto for difícil, deve-se trazer penas de parakau (papagaio, caturrita), pois o nhe'é se encantará com a beleza das penas e trará seu corpinho para fora, para poder olhar melhor.
\end{abstract}

Mãe e avó da gestante acompanham o parto e é comum que uma delas seja a parteira [mbodja'úa]. Dentre as mulheres jovens, apenas podem acompanhar aquelas que sejam aprendizes de kunhã karaí. "É desejável que o pai participe do parto e ajude com a placenta, pois o bebê ao nascer procurará o pai, especialmente se for um menino, e não o encontrando, se aproximará de outro parente masculino, e pode se ligar definitivamente a ele e perder-se do pai” (MELLO, 2006: 148).

Imediatamente após o parto sucedem-se alguns cuidados com a placenta que deve ser enterrada: "Não pode ser jogada no rio nem sobre a terra, para que seres da água ou urubus não tenham contato com ela. Mesmo enterrada, deve-se cuidar para que não seja comida por ratos. Crianças que nascem em hospitais, onde a placenta é jogada no lixo, são mais frágeis, pois o nhe’é fica perdido da família" (MELLO, 2006: 149). Ana Affonso (2014) relata a surpresa de um de seus interlocutores ao saber que nos hospitais as placentas eram jogadas no lixo: "Ele achou a idéia bem sinistra. Disse que desse jeito qualquer animal poderia comer um pedaço de placenta - urubu, cachorro, minhoca -, e sendo assim 'comprar' (ojogua) o nhe $\dddot{e}$ da criança" (AFFONSO, 2014: 94).

O sangue é um canal de sobrenatureza, durante a gravidez, o sangue que normalmente escorre concentra-se no corpo da mulher, acumula-se na placenta e potencializa as possibilidades de comunicações sobrenaturais, expelida quando o bebê nasce [e por isso tamanho cuidado em enterrá-la]. A placenta poderia ser um indicativo da potencial alteridade presente no corpo feminino. Segundo Belaunde (2008), a placenta poderia ser percebida ainda como um mediador entre o corpo da mãe e o feto, uma espécie de parasita que habita o útero da mulher.

Os riscos das comunicações extra-humanas acionadas pelo sangue que corre no pós-parto são evidenciados pela importância do banho tomado pela criança e pela mãe nesse momento. Pissolato (2007) descreve que "banhar-se" pode significar também "nascer", pois a palavra que designa ambos é a mesma -jau. Após o parto "a mãe deve tomar banho com água de cinza e guiné (também chamada em guarani de peperi) para afastar maus espíritos. A parteira amarra um pano firme na barriga da mãe e ela deve fazer as necessidades perto da casa e enterrar bem" (MELLO, 2006: 149). A criança também é submetida a um banho antes mesmo de ser amamentada: "é um banho que dá início à sua nova condição e inaugura um período de resguardo para seus pais” (PISSOLATO, 2007: 277). Mello (2006) 
destaca que é o banho de cinza que faz o leite derreter no útero [memby] e correr para os seios.

O leite materno é outro aspecto fundamental da concepção de bebês: "Junto com o nhe'e, os nhe'rukuery enviam o tchekamby (leite que alimentará a criança), que fica armazenado no memby junto com o mintãim (feto)" (MELLO, 2006: 145). O leite não é produzido por processos fisiológicos ligados ao corpo humano e tem uma importância maior do que a de apenas uma substância, entendido enquanto aspecto fundamental para a permanência da nhe'e na terra: "A importância do leite materno extrapola a esfera nutricional ou fisiológica do corpo e está diretamente ligada à formação da pessoa no sentido espiritual" (MELLO, 2006: 145).

O processo de tornar-se pessoa não está dado após o nascimento (e em nenhum momento da vida mbya), trata-se de uma produção constante que evoca mãe, pai e parentes em torno de garantir que a nhe'e da criança permaneça na terra. Dentre esses cuidados estão as afecções que meninos e meninas devem incorporar para irem formando um corpo adequado, essas afecções podem ser incorporadas através da alimentação e do uso de determinados objetos:

\begin{abstract}
Não se pode dar carne de filhotes de caça aos recém-nascidos para que não se transfira a afecção dentes fracos, dos primeiros para os segundos. Não é aconselhável que as crianças comam alimentos derivados da variedade do milho denominada avaxi ú (milho preto), para que não tenham problemas de visão, já que a afecção escurecimento poderia transferir-se de um corpo ao outro. (PIERRI, 2013: 182)
\end{abstract}

Em sua tese Assis (2006), aponta para o aspecto inventivo desses usos como parte da criação de cada mbya; por esse motivo não seria possível realizar um inventário de objetos e usos. Em geral, tais produções evocam as características que se quer desenvolver nas crianças, como coragem, tranquilidade, força, equilíbrio, leveza. Grande parte deles voltam-se para um fortalecimento ósseo, para facilitar a verticalidade do bebê.

Após o nascimento da criança, iniciam-se os cuidados voltados a fazer sua $n h e^{\prime} e$ querer permanecer na terra. Os cuidados pós-nascimento acionam mãe e pai de formas distintas, mas ambos devem estar atentos para a alimentação, as atividades e as relações. "O pai deverá ficar cerca de um mês realizando apenas atividades leves. A mãe deve permanecer por cerca de dois meses sem ingerir alimentos com sal. [...] o pai não pode se cansar, pois a criança sente" (ASSIS, 2006: 99). Nessa etapa, os cuidados teriam por foco principal os ossos do bebê, sustentáculos da palavra-alma (nhe'e):

\footnotetext{
Desde o nascimento, os bebês são frequentemente submetidos à defumação da cabeça, especificamente a região da coronilha, com o uso do petyngua/cachimbo. A razão para este procedimento está na concepção de que a fumaça do petyngua possui propriedades estimulantes (princípio vital) e de que a coronilha é a parte da cabeça onde a pessoa recebe inspiração divina para falar e falar com sabedoria. No caso das crianças com menos de um ano, esta região da cabeça ainda está aberta, ou seja, ainda há a fontanela. Isso significa que ela precisa ser ao mesmo tempo protegida e estimulada pelo princípio vital do tatachina/fumaça do tabaco. Trata-se de outro importante cuidado para um elemento considerado fundamental na formação da pessoa Mbyá que consiste na linguagem oral. (ASSIS, 2006: 102)
}

Tais cuidados devem ser mantidos até que a criança passe a dar os primeiros passos. Quando as crianças passam a caminhar, portanto erguem-se, considerase que a nhe'e assentou-se no corpo. As palavras fluem a partir do alinhamento da coluna vertebral. Tal processo pode ser entendido como uma via de mão dupla, ao mesmo tempo em que é o erguer-se que garante que a criança está com seu 
nhe'e assentado, há uma produção corporal para que o nhe'e assente-se sobre o corpo:

\begin{abstract}
A verticalidade contrapõe-se à animalidade - estes, os animais, não andam de forma erguida - e indica que a condição humana, ou humanidade mbyá em especial, advém do erguer-se, firmar-se e assim andar. Coincide com o tempo de manter-se firme, ereto e também das primeiras palavras a nominação de crianças mbyá/ ritual do ñemongaraí. É ao tornar-se ereto e firme que as palavras fluem. Os ossos, em geral, e a coluna vertebral no caso são representativos de uma ideologia de construção corporal, a qual é constituída ao longo da vida mbyá por intervenções alimentares e pela predação de qualidades de outros seres. É o poder da fala que confere aos Mbyá uma ligação imanente com as divindades e por isso o apreço pela oratória e o cuidado com o que se pronuncia. (PRATES, 2013: 186)
\end{abstract}

Prates indica a relação entre milho, ossos e nhe'e. Parte do nhemongarai envolve animar o princípio vital do milho e consumir o mbojapé (pão feito do milho) na quantidade de crianças que foram nomeadas (ASSIS, 2006). "A importância do avati/ milho para os Mbya constitui ponto central para discutirmos a imanência entre subsistência e dimensão simbólica" (PRATES, 2013: 148). Na narrativa mítica, é ao alimentar uma coruja (Nhanderu) com mbojapé que Nhandecy descobre estar grávida e é convidada a ir viver na morada celeste (relato que depois se desdobra em suas comunicações com o feto, Kuaray). Prates destaca a importância do milho (avati) no processo de produção corporal das crianças:

O ritual do ñemongarai/ nominação coincide com a colheita do milho e, assim como o
alto da cabeça das crianças, também tem suas sementes enfumaçadas pelo petynguá.
O avati, antes de alimento para o corpo, constitui alimento espiritual e pertence à
classe dos prescritos nos tabus alimentares. Sua forma de cultivo e cocção conta com
intervenções no plano das divindades. (PRATES, 2013:148)

Da couvade até a nominação das crianças, seria o período em que o pai teria uma participação maior nos cuidados com a produção do corpo do bebê (JESUS, 2015). Durante os primeiros anos de vida, a nhe'e da criança acompanha principalmente o pai (PIERRI, 2013), motivo pelo qual este precisaria conversar com a nhe'e da criança, falar sobre suas viagens, indicar os caminhos que vai seguir. Precisa estar atento, pois de certa forma seria como se a nhe'e estivesse sempre presente. Benites descreve: " Para o pai, as crianças tem ligação mais próxima com o umbigo, como se fosse uma corda que liga a criança ao pai" (BENITES, 2018:12). Além de acompanhar o pai, a nhe'e do bebê sofreria as ações em que este se engaja, receberia as afecções dos alimentos ingeridos, dos objetos utilizados, aquilo que o pai faz replicaria no bebê.

Para Assis (2006), a produção da pessoa Mbya passa pelo nascimento e pela criação de filha/os. A autora narra o caso de uma liderança que pretendia ser o representante político de seu grupo em uma instância indígena, anseio imediatamente frustrado por seu pai ao dizer que se nem filho ele tinha ainda, não poderia pretender representar algo ou alguém. Também a alcunha de kunhã karaí é uma categoria de geração e status social que passa por ter tido ou criado crianças (mesmo quando tal termo refere a mulheres xamãs ele engloba o critério anterior). As crianças seriam um indicativo de que os deuses estão sendo generosos com os humanos enviando suas nhe'e.

Jesus (2015) indica que o processo de criar crianças é fundamental para a manutenção do nhande rekó (jeito guarani). Implica guiar nhe'e kuery (coletivo de $n h e^{\prime} e$ ) nessa terra, o que depende da adequada produção de corpos masculinos e femininos, cuja responsabilidade é em grande medida atribuída às mulheres. Tal aspecto evidencia que o feminino engloba o masculino no processo de criação 
de crianças. Apesar de a complementariedade ser apontada enquanto modelo ideal haveria uma distância entre tais narrativas e o cotidiano das aldeias:

\begin{abstract}
A complementariedade feminina e masculina é mencionada nas narrativas míticas como fator primordial nos aconselhamentos acerca do modo ideal de uniões matrimoniais. Apesar disto, no cotidiano da aldeia o idealismo encontra pouca ressonância e a tarefa de criar crianças, de produzir pessoas mbya dentro do nhande rekó mostra-se como uma tarefa majoritariamente feminina. (JESUS, 2015: 32)
\end{abstract}

Acerca da agência feminina na criação de crianças, Jesus relata ter encontrado em campo diversas conformações de mulheres criando crianças sem estar num casamento, só com a ajuda de parentes: aquelas que não queriam casar, mas queriam criar crianças; mulheres que não quiseram engravidar, mas que tinham filhos de criação; mulheres mais velhas que se mudavam sozinhas com os filhos mais velhos. Caberia às mulheres ainda uma ideia de cuidado, de estar bem, atenção "que outras mulheres podem prestar a uma parente grávida que se encontra sozinha na tarefa de criar uma criança" (JESUS, 2015: 135). Como observa Belaunde: "Las redes de solidaridad entre personas del mismo género son una fuente segura de autonomía para las mujeres y los hombres, y disminuye el estrés de la relación conyugal” (BELAUNDE, 2008: 20).

\title{
Considerações finais
}

A composição da pessoa mbya é atravessada por substâncias e relações, substâncias que operam como veículos que conectam seres, que ativam parentescos, enfraquecem e fortalecem corpos. O modo como a corporalidade é pensada aqui se distancia de uma perspectiva que suporia uma universalidade dos corpos e uma multiplicidade dos sentidos. Seria possível sugerir uma aproximação dessa abordagem com a perspectiva mbya pensando que uma pessoa feminina ou masculina seria a particularização de um ponto de vista em meio a outros tantos possíveis e que permanece permeada pela constante necessidade de ser estabilizada através da própria produção corporal. Mesmo os processos de criar crianças operam como uma espécie de continuidade de toda essa produção, o que fica evidente pelo modo como ter tido ou não filhos mobiliza diferentes categorias internas.

O que ressoa aqui é a ideia de perspectivas e afecções em torno de corporalidades, uma perspectiva feminina pode incorporar afecções "masculinas", uma perspectiva pode até mesmo substituir outra. É possível sofrer jepota e incorporar perspectivas alheias, transformando-se em outros seres. Pensar essas relações considerando tratar-se de um mundo povoado de alteridades passíveis de ativação, significa que diversas feminilidades e masculinidades estão disponíveis, contidas em corpos outros - tal como sugere McCallum (2001).

O modo como essas relações se desdobram no cotidiano aparece, por exemplo, nos cuidados com as afecções desejadas ou não para as crianças. No modo como homens e mulheres compartilham substâncias e fabricam seus corpos com ações que desencadeiam efeitos em outras pessoas e, portanto, não podem ser pensadas de maneira isolada. O que se torna evidente pelos riscos que todos aqueles de um mesmo grupo correm caso uma mulher ou um homem não cumpram seus períodos de resguardo. Pessoas mbya vão tendo seus corpos produzidos ao longo da vida, em meio a essa série de afecções passíveis de incorporação, de acordo com aquilo que deve ser eclipsado ou ativado em cada um, tal como percebemos no recorte feito neste artigo. 
Recebido em 29 de janeiro de 2020.

Aprovado em 31 de maio de 2020.

\section{Referências}

AFFONSO, Ana Maria. De pessoas e palavras entre os Guarani-Mbya. Tese de Doutorado, Antropologia, UFF, 2014.

ASSIS, Valéria. Dádiva, mercadoria e pessoa: as trocas na constituição do mundo social Mbyá-Guarani. Tese de doutorado, Antropologia, UFRGS, 2006.

BELAUNDE, Luisa Elvira. El recuerdo de Luna: Género, sangre y memoria entre los pueblos amazónicos. Lima: UNMSM, 2008.

BENITES, Sandra. Viver na língua guarani nhandewa (mulher falando). Dissertação de Mestrado, Antropologia, UFRJ, 2018.

CICCARONE, Celeste. Drama e sensibilidade: Migração, xamanismo e mulheres Mbya Guarani. Tese de Doutorado, Ciências Sociais, PUC-SP, 2001.

CLASTRES, Hélène. Terra Sem Mal. São Paulo: Brasiliense, 1978.

CLASTRES, Pierre. Crônica dos Índios Guayaki: O que sabem os Aché, caçadores nômades do Paraguai. Rio de Janeiro: Editora 34, 1995.

FERREIRA, Luciane. Saúde e relações de gênero: uma reflexão sobre os desafios para a implantação de políticas públicas de atenção à saúde da mulher indígena. Ciência e Saúde Coletiva, 18 (4): 1151-1159, 2013.

HEURICH, Guilherme. Outras alegrias: Parentesco e festas Mbya. Dissertação de Mestrado, Antropologia, UFRJ, 2011.

JESUS, Suzana de. Pessoas na medida: Processos de circulação de saberes sobre o Nhande Reko Guarani na região das Missões. Tese de Doutorado, Antropologia, UFSC, 2015.

LEWKOWICZ, Rita. A hora certa para nascer: um estudo antropológico sobre o parto hospitalar entre mulheres mbyá-guarani no sul do Brasil. Dissertação de Mestrado, Antropologia, UFRGS, 2016.

LIMA, Tânia Stolze. O dois e seu múltiplo: reflexões sobre o perspectivismo em uma cosmologia tupi. Mana, 2 (2): 21-47, 1996.

McCALLUM, Cecília. Gender and Sociality in Amazonia: How Real People are Made. New York: Oxford, 2001.

MELLO, Flávia. Aetcha nhanderukuery karai retarã: Entre deuses e animais: xamanismo, parentesco e transformação entre os Chiripá e Mbyá Guarani. Tese de Doutorado, Antropologia, UFSC, 2006.

MELLO, Flávia. Aata tape rupy, seguindo pela estrada: uma investigação dos deslocamentos territoriais de famélias mbya-guarani do sul do Brasil. Dissertação de mestrado, Antropologia, UFSC, 2001.

MENDES JR., Rafael. A saga rumo ao norte e os outros do caminho: a busca da terra sem mal entre os Guarani contemporâneos. Tese de doutorado, Antropologia, UFRJ, 2016. 
PIERRI, Daniel. O perecível e o imperecível. Dissertação de mestrado, Antropologia, USP, 2013.

PISSOLATO, Elizabeth. A duração da pessoa: Mobilidade, parentesco e xamanismo mbya (guarani). São Paulo: Unesp, 2007.

PRADELLA, Luiz Gustavo. Entre os seus e os outros: horizonte, mobilidade e cosmopolítica guarani. Dissertação de mestrado, Antropologia, UFRGS, 2009.

PRATES, Maria Paula. Da instabilidade e dos afetos: pacificando relações, amansando outros: cosmopolítica guarani-mbyá (Lago Guaíba/RSBrasil). Tese de Doutorado, Antropologia, UFRGS, 2013.

TEMPASS, Martin. Orerémbiú: a relação das práticas alimentares e seus significados com a identidade étnica e a cosmologia Mbyá-Guarani. Dissertação de Mestrado, Antropologia, UFRGS, 2005.

VIVEIROS DE CASTRO, Eduardo. A Inconstância da Alma Selvagem. São Paulo: Cosac Naify, 2011.

VIVEIROS DE CASTRO, Eduardo. Os pronomes cosmológicos e o perspectivismo ameríndio. Mana, 2 (2): 115-144, 1996. 